\title{
Analisis Efisiensi Penggunaan Teknologi Aspal Daur Ulang Pada Jalan Tol Elevated Ir. Wiyoto Wiyono
}

\author{
Yogi Oktopianto $^{1}$, Dwi Wahyu Hidayat ${ }^{2}$ \\ ${ }^{1}$ Politeknik Keselamatan Transportasi Jalan, Tegal \\ ${ }^{2}$ Politeknik Transportasi Darat, Bali \\ E-mail: yogi.oktopianto@pktj.ac.id
}

Received 11 September 2020; Reviewed 09 October 2020; Accepted 05 November 2020

Journal Homepage: http://jurnal.borneo.ac.id/index.php/borneoengineering

\begin{abstract}
The use of recycling technologies to the principles of green roads should get priority. Reclaimed Asphalt Pavement (RAP) has not been used properly is a problem in this study. Hotmix Recycling is a recycling technique that can be applied to road pavement rehabilitation and maintenance. The research was conducted to determine the cost efficiency of recycled asphalt. The method used in this research is to analyze the unit price of conventional asphalt maintenance and to analyze the unit price of recycled asphalt in order to find out how much efficiency is obtained of asphalt pavement recycled. The results showed that the cost of conventional asphalt is Rp.1,160,000 per ton and the price of recycled asphalt is Rp.915,000 per ton, there is a savings of Rp. 245,000 per ton, The use of recycled asphalt technology in the periodic asphalt of the Ir. Wiyoto Wiyono toll roads can save operational and maintenance costs of $R p$. 3,013,500,000.00
\end{abstract}

Keywords: Hot mix recycling, green roads, RAP

\begin{abstract}
Abstrak
Penggunaan teknologi daur ulang dalam menerapkan prinsip green roads perlu mendapat prioritas. Reclaimed Asphalt Pavement (RAP) belum termanfaatkan dengan baik menjadi permasalahan dalam penelitian ini. Hotmix Recycling merupakan suatu teknik daur ulang yang dapat diterapkan pada rehabilitasi dan pemeliharaan perkerasan jalan. Penelitian dilakukan untuk mengetahui efisiensi biaya aspal daur ulang. Metode yang digunakan dalam penelitian ini dengan membuat analisa harga satuan pada pekerjaan pemeliharaan aspal konvensional dan membuat analisa harga satuan pada aspal daur ulang untung mengetahui seberapa besar efisiensi yang di dapatkan dari pemanfaatan material bekas. Hasil penelitian didapatkan biaya aspal konvensional Rp.1.160.000,00 per ton dan harga aspal daur ulang Rp.915.000,00 per ton terdapat penghematan sebesar Rp.245.000,00 per ton, dengan demikian penggunaan teknologi aspal daur ulang pada pekerjaan aspal periodik Jalan Tol Ir. Wiyoto Wiyono dapat menghemat biaya operasional dan pemeliharaan sebesar Rp.3.013.500.000,00
\end{abstract}

Kata kunci: Hot mix recycling, green roads, RAP

\section{Pendahuluan}

Keterbatasan biaya pemeliharaan serta hasil kupasan lapis permukaan beraspal yang biasa disebut Reclaimed Asphalt Pavement (RAP) belum termanfaatkan dengan baik, bahkan bisa menyebabkan masalah-masalah lain. Alternatif untuk mengatasi kendala biaya pemeliharaan adalah pemanfaatan 
RAP, khususnya untuk pekerjaan pemeliharaan (perbaikan atau rekonstruksi) jalan dengan menggunakan metode cut and fill. Metode ini merupakan green technology karena memanfaatkan limbah dari perkerasan jalan. Beberapa penelitian telah menunjukkan bahwa karakteristik pemanfaatan aspal daur ulang. Semakin banyak bahan peremaja dalam campuran aspal daur ulang akan menyebabkan menurunnya nilai stabilitas campuran yang kemungkinan disebabkan oleh sifatsifat kepadatan campuran yang semakin kecil. Kadar Maksimum bahan peremaja yang masih memenuhi spesifikasi nilai Stabilitas Marshall adalah 35,29\% (Kasan, 2007).

Penelitian tentang studi nilai stabilitas dan Marshall dari Campuran Beton Aspal yang didaur ulang telah dilakukan melalui beberapa tahap percobaan dan skenario mendapatkan bahwa nilai kadar aspal optimum campuran beton aspal daur ulang cenderung menurun dengan bertambahnya kadar bahan peremaja yang digunakan (Kasan, 2009). Berbagai penelitian aspal daur ulang telah dilakukan untuk mengetahui sejauh mana karakteristik aspal beton hasil daur ulang dapat digunakan kembali sebagai lapis permukaan. Karakteristik Marshall untuk campuran daur ulang rata-rata memenuhi persyaratan, kecuali untuk parameter VIM yang nilainya terlalu besar, hal ini dapat disebabkan oleh daya ikat aspal yang sudah berkurang yang menyebabkan ronggarongga dalam campuran tidak terisi dengan baik (Alamsyah, 2012).

Pada hasil lain penelitian kinerja campuran beton aspal daur ulang (RAP) dan campuran standar menunjukkan bahwa kepadatan, persentase rongga terhadap agregat (VMA), stabilitas, kelelehan, marshall quotient Persentase rongga terhadap campuran (VIM) dan persentase rongga terisi aspal (VFB) memenuhi spesifikasi Bina Marga 2010, dengan Kadar Aspal Optimum yang didapatkan dari uji Marshall RAP dan campuran standar masing-masing sebesar 6,79\% dan 6,9\% (Wiyono, 2015).

Komposisi atau formula terbaik campuran aspal beton dengan menggunakan Reclaimed Asphalt Pavement (RAP) yaitu : Batu pecah 1-2 = 12\%, Batu Pecah 0,5 $-1=28,37 \%$, Abu batu $=18,56 \%$, RAP $=43.14 \%$, Aspal Minyak pen 60/70 $=5,91 \%$ dengan Kadar Aspal Optimum (KAO) sebesar 7,98\% (Maryam H, 2018). Penelitian yang serupa secara teknis telah dilakukan pada jalan tol elevated Ir. Wiyoto Wiyono dengan hasil menunjukkan sangat baik dengan formulasi 30:70 parameter stability hotmix recycling lebih tinggi dibandingkan hotmix konvensional berturut-turut $1677,98 \mathrm{~kg}$ dan $1600 \mathrm{~kg}$ dengan standar minimum sebesar $1100 \mathrm{~kg}$ (Oktopianto \& Fathullah, 2020).

Dengan menggunakan teknologi daur ulang ditinjau dari biaya terdapat penghematan sebesar 35 $40 \%$ per ton dibandingkan dengan menggunakan teknologi konvensional (Bria et al., 2016). Secara teknis pemanfaatan aspal daur ulang pada jalan tol elevated Ir. Wiyoto Wiyono telah dilakukan pengujian sampai tahap validasi hingga semua memenuhi spesifikasi yang ditetapkan. Tidak hanya secara teknis pemanfaatan aspal daur ulang juga harus diperhitungkan secara biaya. Tujuan dari penelitian ini yaitu untuk mengetahui efisiensi biaya terhadap penggunaan aspal daur ulang pada program operasional dan pemeliharaan jalan tol elevated Ir. Wiyoto Wiyono.

\section{Metode Penelitian}

Jenis penelitian ini adalah eksperimental dengan melakukan pengujian laboratorium terhadap material aspal. Stok material Reclaimed Asphalt Pavement (RAP) mentah yang digunakan berasal dari lokasi Tol milik PT. Citra Marga Nusaphala Persada, Tbk, yang selanjutnya dilakukan observasi terhadap nilai-nilai karakteristik bahan di laboratorium. Tahapan selanjutnya dalam penelitian ini dengan membuat analisa harga satuan pada pekerjaan pemeliharaan aspal 
konvensional dan membuat analisa harga satuan pada aspal daur ulang untung mengetahui seberapa besar efisiensi yang didapatkan dari pemanfaatan material bekas pada pekerjaan aspal periodik. Analisa harga satuan yang digunakan mengacu pada harga satuan pekerjaan DKI Jakarta tahun 2020.

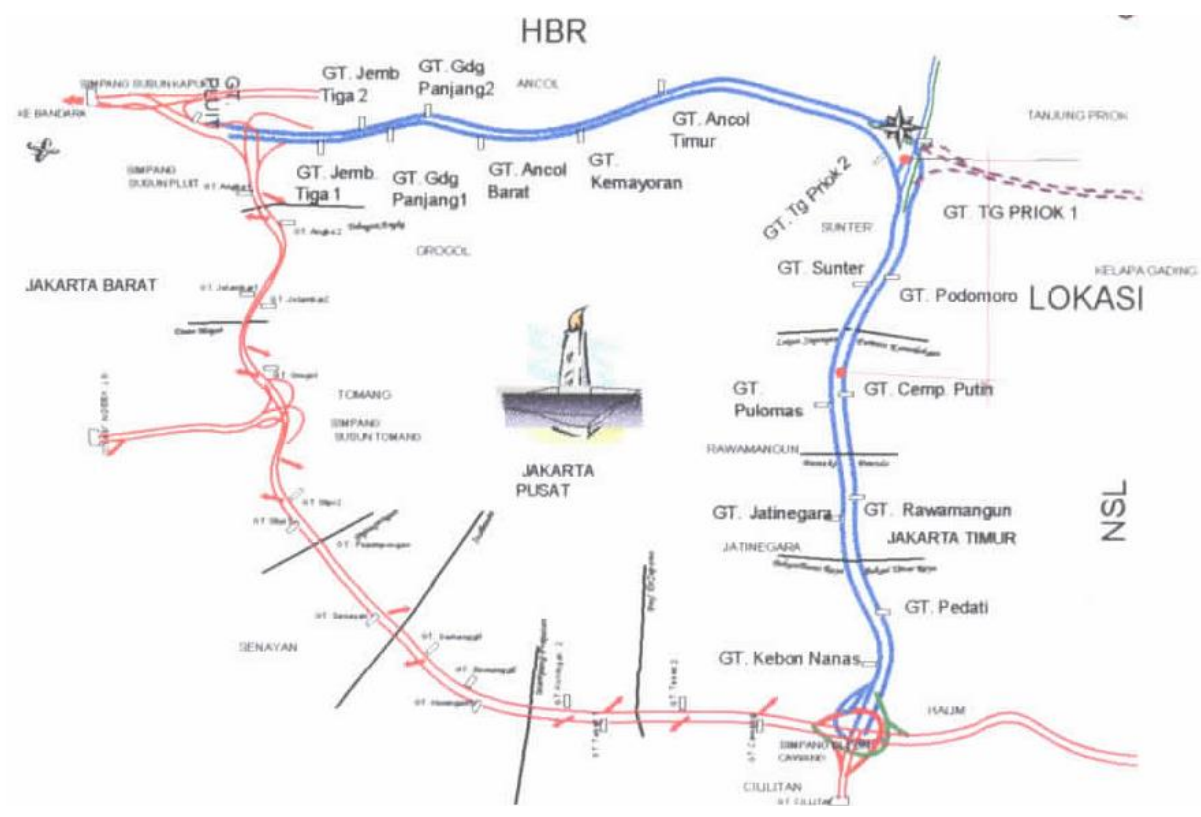

Gambar. 1 Lokasi Penelitian Jalan Tol Ir. Wiyoto Wiyono

\section{Hasil dan Pembahasan}

Penelitian diawali dengan pengujian variasi fresh aspal + aspal RAP. Selanjutnya dilakukan pengujian properties dengan beberapa variasi fresh bitumen dengan bitumen murni ex-RAP.

Tabel 1. Hasil Uji Penetrasi, Titik Lembek dan Daktilitas variasi bitumen murni dan RAP

\begin{tabular}{|c|c|c|c|c|c|}
\hline No & Item variasi & Penetrasi & Titik Lembek & Daktilitas & Keterangan \\
\hline 1 & Bitumen Ex-RAP & 16,33 & 76,68 & 9,5 & NOT OK \\
\hline 2 & $\begin{array}{l}\text { Bitumen Ex-RAP +Additiv } \\
\text { Iterlene } 4 \%\end{array}$ & 29,13 & 64,75 & 23,75 & NOT OK \\
\hline 3 & $\begin{array}{l}\text { Bitumen Ex-RAP 30\% + } \\
\text { Bitumen Fresh 70\% }\end{array}$ & 51,55 & 57,94 & 125,5 & NOT OK \\
\hline 4 & $\begin{array}{l}\text { Bitumen Ex-RAP 30\% } \\
\text { + Bitumen Fresh } 70 \% \\
\text { + Additive iterlene 4\% }\end{array}$ & 60,80 & 55,75 & 135 & OK \\
\hline 5 & $\begin{array}{l}\text { Bitumen Ex-RAP 20\% + } \\
\text { Bitumen Fresh } 80 \%\end{array}$ & 55,15 & 56,75 & 137,5 & NOT OK \\
\hline 6 & $\begin{array}{l}\text { Bitumen Ex-RAP } 20 \% \\
\text { + Bitumen Fresh } 80 \% \\
\text { + Additive iterlene } 4 \%\end{array}$ & 63,25 & 55,25 & $>140$ & OK \\
\hline \multicolumn{2}{|c|}{ Spesifikasi } & $60-70$ & $48-58$ & $\geq 100$ & - \\
\hline
\end{tabular}

Tujuan dilakukannya pengujian variasi ini adalah untuk mendapatkan variasi yang terbaik yang memenuhi spesifikasi bitumen keras penetrasi 60/70. Adapun variasi fresh bitumen dan bitumen murni ex-RAP sebagai berikut: 
1. Bitumen Murni Ex-RAP

2. Bitumen Murni Ex-RAP + Additive interlene 4\%

3. Bitumen Murni Ex-RAP 30\% + Bitumen Fresh 70\%

4. Bitumen Murni Ex-RAP 30\% + Bitumen Fresh 70\% + Additive interlene 4\%

5. Bitumen Murni Ex-RAP $20 \%+$ Bitumen Fresh $80 \%$

6. Bitumen Murni Ex-RAP 20\% + Bitumen Fresh 80\% + Additive interlene 4\%

Parameter yang diuji dari masing-masing variasi diatas adalah Penetrasi, titik lembek dan daktilitas.

Berdasarkan hasil pengujian parameter diperoleh hasil bahwa variasi yang memenuhi spesifikasi parameter penetrasi, titik lembek, dan daktilitas adalah variasi

1. Bitumen Murni Ex-RAP 30\% + Bitumen Fresh 70\% + Additive interlene 4\%

2. Bitumen Murni Ex-RAP $20 \%+$ Bitumen Fresh $80 \%$ + Additive interlene $4 \%$

\section{Tabel 2. Analisa Harga Satuan Pekerjaan Aspal Konvensional}

\begin{tabular}{|c|c|c|c|c|c|}
\hline No & Uraian & Volume & Satuan & Harga Satuan & Jumlah \\
\hline $\mathbf{A}$ & Material & & & & \\
\hline 1 & Asphalt Pen 60/70 & 6,41 & ton & $8.350 .000,00$ & $53.523 .500,00$ \\
\hline 2 & Agregat kasar & 43,47 & $\mathrm{~m}^{3}$ & $220.000,00$ & $9.563 .400,00$ \\
\hline 3 & Agregat Halus & 29,34 & $\mathrm{~m}^{3}$ & $220.000,00$ & $6.454 .800,00$ \\
\hline \multirow[t]{2}{*}{4} & Filler (Semen) & $1.086,80$ & $\mathrm{~kg}$ & $1.360,00$ & $1.478 .048,00$ \\
\hline & & & & Sub Total A & 71.019.748,00 \\
\hline B & Peralatan & & & & \\
\hline 1 & Asphalt Mixing Plant (AMP) & 0,43 & hari & $15.000 .000,00$ & $6.450 .000,00$ \\
\hline 2 & Asphalt Finisher & 0,43 & hari & $5.500 .000,00$ & $2.365 .000,00$ \\
\hline 3 & Tandem Roller & 0,43 & hari & $3.200 .000,00$ & $1.376 .000,00$ \\
\hline 4 & Pneumatic Tyred Roller & 0,87 & hari & $3.400 .000,00$ & $2.958 .000,00$ \\
\hline 5 & Dump Truck & 5,00 & hari & $1.500 .000,00$ & $7.500 .000,00$ \\
\hline \multirow[t]{2}{*}{6} & Whell Loader & 0,43 & hari & $3.000 .000,00$ & $1.290 .000,00$ \\
\hline & & & & Sub Total B & 21.939.000,00 \\
\hline $\mathbf{C}$ & Tenaga Kerja & & & & \\
\hline 1 & Pekerja & 10,00 & hok & $122.181,00$ & $1.221 .810,00$ \\
\hline 2 & Operator & 4,00 & hok & $122.181,00$ & $488.724,00$ \\
\hline 3 & Sopir & 2,00 & hok & $146.617,00$ & $284.436,98$ \\
\hline 4 & Mekanik & 1,00 & hok & $146.617,00$ & $146.617,00$ \\
\hline \multirow[t]{2}{*}{5} & Mandor & 0,20 & hok & $158.835,00$ & $31.449,33$ \\
\hline & & & & Sub Total C & 2.173.037,31 \\
\hline D & Lain-lain & & & & \\
\hline 1 & Solar Industri & $1.956,24$ & liter & $9.770,00$ & $19.112 .464,80$ \\
\hline 2 & Pelumas & 1,00 & 1s & $150.000,00$ & $150.000,00$ \\
\hline \multirow[t]{2}{*}{3} & Tol & 1,00 & $1 \mathrm{~s}$ & $250.000,00$ & $250.000,00$ \\
\hline & & & & Sub Total D & $19.512 .464,80$ \\
\hline \multicolumn{2}{|c|}{ Jumlah } & & & & 114.644.250,11 \\
\hline \multicolumn{2}{|c|}{ Jasa $10 \%$} & & & & $11.464 .425,01$ \\
\hline \multirow{2}{*}{\multicolumn{2}{|c|}{$\begin{array}{l}\text { Total } \\
\text { Harga Satuan Pekerjaan Per Ton }\end{array}$}} & & & & 126.108.675,12 \\
\hline & & & & & $1.160 .366,90$ \\
\hline \multicolumn{2}{|c|}{ Harga Satuan Pekerjaan Dibulatkan } & & & & $1.160 .000,00$ \\
\hline
\end{tabular}

Sumber : Hasil Analisis, 2020 
Adapun dengan pertimbangan biaya produksi, biaya operasional, serta besarnya RAP yang dapat di recycle maka variasi Bitumen Murni Ex-RAP 30\% + Bitumen Fresh 70\% + Additive interlene 4\% dapat dipilih sebagai kombinasi yang memenuhi aspek lingkungan, mutu, dan biaya.

Dalam melakukan analisa ekonomi, langkah pertama yang perlu dilakukan adalah menghitung besarnya biaya satuan pekerjaan per meter persegi. Menghitung biaya satuan pekerjaan berdasarkan pada kebutuhan tenaga kerja, perlatan dan bahan. Analisa harga satuan pekerjaan aspal konvensional dapat dilihat pada tabel 2.

Tabel 3. Analisa Harga Satuan Pekerjaan Aspal Daur Ulang

No Uraian Volume Satuan Harga Satuan Jumlah

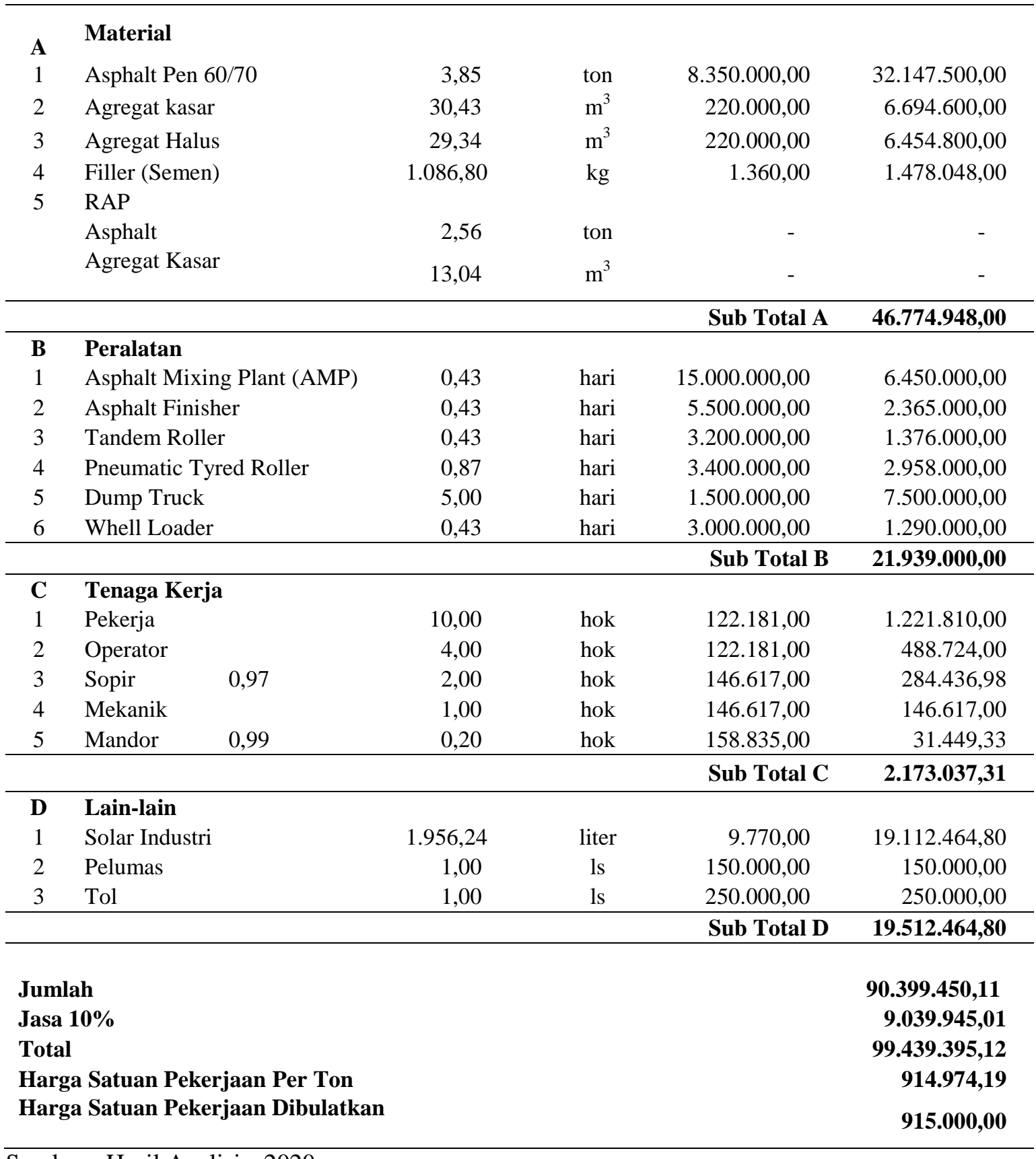

Sumber : Hasil Analisis, 2020 
Pada analisa harga satuan pekerjaan aspal konvensional dan aspal daur ulang memiliki perbedaan di material RAP. Material RAP bernilai 0 karena pada pelaksanaan pemeliharaan dengan metode daur ulang material scrapping akan diolah lalu digunakan sebagai material filling sehingga tidak menimbulkan biaya dan dapat mengurangi pemakaian material baru.

Dengan demikian maka ditinjau dari biaya aspal konvensional Rp. 1.160.000,00 per ton dan harga aspal daur ulang Rp. 915.000,00 per ton terdapat penghematan sebesar 245.000,00 per ton dibandingkan dengan menggunakan aspal konvensional. Oleh karena itu, pada aspal periodik sangat tepat jika menggunakan teknologi aspal daur ulang pada perkerasan jalan dengan terlebih dahulu melakukan pengujian terhadap material lama. Perbandingan biaya pemeliharaan antara menggunakan aspal konvensional dan aspal daur ulang pada pekerjaan aspal periodik dapat dilihat pada tabel 4.

Tabel 4. Efisiensi Penggunaan Aspal Daur Ulang

\begin{tabular}{cccccc}
\hline No & Uraian & $\begin{array}{c}\text { Volume } \\
\text { (Ton) }\end{array}$ & $\begin{array}{c}\text { Harga Aspal } \\
\text { Konvensional }\end{array}$ & $\begin{array}{c}\text { Harga Daur } \\
\text { Ulang }\end{array}$ & Jumlah \\
\hline \multirow{2}{*}{1} & $\begin{array}{l}\text { Scrapping \& } \\
\text { Filling Aspal }\end{array}$ & 12300 & $1.160 .000,00$ & & $14.268 .000 .000,00$ \\
& $\begin{array}{l}\text { Scrapping \& } \\
2\end{array}$ & 12300 & & $915.000,00$ & $11.254 .500 .000,00$ \\
\hline & Filling Aspal & \multicolumn{2}{c}{ Penghematan Biaya } & $3.013 .500 .000,00$ \\
\hline
\end{tabular}

Sumber : Hasil Analisis, 2020

Berdasarkan analisis biaya yang dilakukan penggunaan teknologi aspal daur ulang pada pekerjaan aspal periodik jalan tol elevated dapat menghemat biaya pemeliharaan sebesar Rp. 3.013.500.000,00.

\section{Kesimpulan}

Berdasarkan formulasi antara RAP dan fresh material 30:70 didapatkan biaya aspal konvensional Rp.1.160.000,00 per ton dan harga aspal daur ulang Rp.915.000,00 per ton terdapat penghematan sebesar Rp.245.000,00 per ton, dengan demikian penggunaan teknologi aspal daur ulang pada pekerjaan aspal periodik jalan tol Ir. Wiyoto Wiyono dapat menghemat biaya operasional dan pemeliharaan sebesar Rp.3.013.500.000,00

\section{Saran}

Perlu dilakukan penelitian lebih lanjut untuk mendapatkan proporsi maksimal antara RAP dan fresh material dengan penggunaan bahan peremaja campuran lainya sehingga penghematan biaya pemeliharaan pada pekerjaan scrapping and filling aspal dengan metode daur ulang lebih maksimal.

\section{Daftar Pustaka}

Al-Qadi, I. L., Elseifi, M., \& Carpenter, S. H. (2007). Reclaimed asphalt pavement - A literature review. Federal Highway Administration. https://doi.org/http://hdl.handle.net/2142/46007

Alamsyah, A. A. (2012). Korelasi Antara Penambahan Aspal Minyak Pada Campuran Perkerasan Aspal Beton Hasil Daur Ulang Terhadap Karakteristik Marshall. 8(September), 132-139. 
Anthonissen, J., Van den bergh, W., \& Braet, J. (2016). Review and environmental impact assessment of green technologies for base courses in bituminous pavements. In Environmental Impact Assessment Review. https://doi.org/10.1016/j.eiar.2016.04.005

Aurangzeb, Q., Al-Qadi, I. L., Ozer, H., \& Yang, R. (2014). Hybrid life cycle assessment for asphalt mixtures with high RAP content. Resources, Conservation and Recycling. https://doi.org/10.1016/j.resconrec.2013.12.004

Baghaee Moghaddam, T., \& Baaj, H. (2016). The use of rejuvenating agents in production of recycled hot mix asphalt: A systematic review. In Construction and Building Materials. https://doi.org/10.1016/j.conbuildmat.2016.04.015

Bowers, B. F., Huang, B., Shu, X., \& Miller, B. C. (2014). Investigation of Reclaimed Asphalt Pavement blending efficiency through GPC and FTIR. Construction and Building Materials. https://doi.org/10.1016/j.conbuildmat.2013.10.003

Bria, M., Muda, A. H., \& Dumin, L. (2016). Penggunaan Teknologi Daur Ulang Perkerasan Aspal Wisata Di Timor. 26-35.

Cong, P., Zhang, Y., \& Liu, N. (2016). Investigation of the properties of asphalt mixtures incorporating reclaimed SBS modified asphalt pavement. Construction and Building Materials. https://doi.org/10.1016/j.conbuildmat.2016.03.059

Dony, A., Colin, J., Bruneau, D., Drouadaine, I., \& Navaro, J. (2013). Reclaimed asphalt concretes with high recycling rates: Changes in reclaimed binder properties according to rejuvenating agent. Construction and Building Materials. https://doi.org/10.1016/j.conbuildmat.2012.11.031

Huang, B., Li, G., Vukosavljevic, D., Shu, X., \& Egan, B. K. (2005). Laboratory investigation of mixing hot-mix asphalt with reclaimed asphalt pavement. Transportation Research Record. https://doi.org/10.3141/1929-05

Hussain, A., \& Qiu, Y. (2013). Effect of reclaimed asphalt pavement on the properties of asphalt binders. Procedia Engineering. https://doi.org/10.1016/j.proeng.2013.03.077

Kasan, M. (2007). Karakteristik Stabilitas dan Stabilitas Sisa Campuran Beton Aspal Daur Ulang. Staf Pengajar Jurusan Teknik Sipil Fakultas Teknik Universitas Tadulako, Palu.

Kasan, M. (2009). Studi karakteristik volumetrik campuran beton aspal daur ulang (Study of volumetric characteristics of recycled asphalt concrete mixtures). Smartek, 7(3), 152-165.

Maryam H. (2018). Analisis Formulasi Pemanfaatan Material Daur. 3(1), 79-94.

McDaniel, R., \& Michael Anderson, R. (2001). NCHRP REPORT 452 - Recommended Use of Reclaimed Asphalt Pavement in the Superpave Mix Design Method: Technician's Manual TRANSPORTATION. In National Cooperative Highway Research Program.

Oktopianto, Y., \& Fathullah, M. (2020). Analisis Formulasi Mutu Hotmix Konvensional Dan Hotmix Recycling Pada Jalan Tol Ir. Wiyoto Wiyono. Jurnal Keselamatan Transportasi Jalan (Indonesian Journal of Road Safety), 7(1), 59-64. https://doi.org/10.46447/ktj.v7i1.76

Pradyumna, T. A., Mittal, A., \& Jain, P. K. (2013). Characterization of Reclaimed Asphalt Pavement (RAP) for Use in Bituminous Road Construction. Procedia - Social and Behavioral 
Sciences. https://doi.org/10.1016/j.sbspro.2013.11.211

Pramudyo, C. (2013). the Investigation on Mix Proportion' S Characteristic of Recycle Material Made of Rap ( Reclaimed Asphalt Pavement) Artifisial Investigasi Karakteristik Campuran Daur Ulang Menggunakan Bahan Rap ( Reclaimed Asphalt Pavement) Artifisial. 1-3.

Vidal, R., Moliner, E., Martínez, G., \& Rubio, M. C. (2013). Life cycle assessment of hot mix asphalt and zeolite-based warm mix asphalt with reclaimed asphalt pavement. Resources, Conservation and Recycling. https://doi.org/10.1016/j.resconrec.2013.02.018

Vislavičius, K., \& Sivilevičius, H. (2013). Effect of reclaimed asphalt pavement gradation variation on the homogeneity of recycled hot-mix asphalt. Archives of Civil and Mechanical Engineering. https://doi.org/10.1016/j.acme.2013.03.003

Widiyanto, A., Panjang, H., \& No, T. T. (2010). Pemanfaatan material tempatan untuk bahan jalan sebagai upaya efisiensi dan penerapan green construction pada pembangunan jalan. 389.

Wiyono, E. (2015). Untuk Daur Ulang Campuran Beton Aspal. 14(1).

Zaumanis, M., Mallick, R. B., \& Frank, R. (2014). 100\% recycled hot mix asphalt: A review and analysis. In Resources, Conservation and Recycling. https://doi.org/10.1016/j.resconrec.2014.07.007 